\title{
Crambe (Crambe hispanica subsp. abyssinica) Genotiplerinin Bazı Bitkisel Özelliklerinin Belirlenmesi
}

\author{
*Yusuf ARSLAN" İlhan SUBAŞI² Hasan KEYVANOĞLU² \\ ${ }^{1}$ Abant İzzet Baysal Üniversitesi, Ziraat ve Doğa Bilimleri Fakültesi, Tarla Bitkileri Bölümü, Bolu \\ ${ }^{2}$ Tarla Bitkileri Merkez Araştırma Enstitüsü Müdürlüğü, Ankara \\ *Sorumlu yazar e-posta (Corresponding author; e-mail): yarslantarm@gmail.com \\ Geliş Tarihi (Received): 04.12.2014 Kabul Tarihi (Accepted): 08.06.0215 \\ Öz \\ Bu çalışma; Crambe genotiplerinin bazı bitkisel özelliklerinin belirlemesi amacıyla Ankara koşullarında \\ Tarla Bitkileri Merkez Araştırma Enstitüsü Müdürlüğü'nün Araştırma ve Uygulama tarlasında 2013 yılında \\ yürütülmüştür. Bu çalışmada materyal olarak ABD Ulusal Gen Bankası'ndan temin edilen 82 adet Crambe \\ (Crambe hispanica subsp. abyssinica) genotipinden elde edilen veriler kullanılmıştır. Crambe bitkisinde, \\ rozette kalma gün sayısı, bin tohum ağırlığı (g), bitki başına tohum verimi ( $\mathrm{g} / \mathrm{bitki})$, tohumda yağ oranı $(\%)$ ve \\ sabit yağ asitleri bileşimi (\%) belirlenmiş̧ir. Araşıırma sonuçlarına göre sapa kalkma gün sayısı 41 gün, bin \\ dane ağırlığı 6,6g, bitki başına tohum verimi $2,3 \mathrm{~g} / \mathrm{bitki}$, tohumda yağ oranı $\% 13,4$, erüsik asit oranı $\% 54$, \\ oleik asit oranı $\% 14,35$, linoleik asit oranı $\% 9,41$ ve linolenik asit oranı $\% 7,59$ olarak belirlenmiştir.
}

Anahtar Kelimeler: Crambe, erüsik asit, sabit yağ asitleri bileşimi, yağ oranı

\section{Determination of Some Plants Characteristics of Crambe (Crambe hispanica subsp. abyssinica) Genotypes}

\begin{abstract}
This study was carried out to determination of some plant characteristics of Crambe genotype under Ankara conditions in the research and experimental fields of the Research Center for the Field Crops in 2013. In this study were used 82 genotypes of Crambe (Crambe hispanica subsp. abyssinica) which obtained from The USA Gene Bank. The number of days remaining in the rosette, 1000 seed weight $(\mathrm{g})$, seed yield per plant (g), seed oil content (\%) and fatty acid composition (\%) of Crambe genotypes. According to the results obtained from this study; duration of the rosette stage 41 days, 1000 seed weight $6,6 \mathrm{~g}$, seed yield per plant $2,3 \mathrm{~g}$, seed oil content $13,4 \%$, erusic acid content $54 \%$, oleic acid content $14,35 \%$, linoleic acid content $9,41 \%$, linolenic acid content $7,59 \%$ were measured in Crambe genotypes.
\end{abstract}

Keywords: Crambe genotypes, erusic acid, fatty acid composition, seed oil content

\section{Giriş}

$\mathrm{D}$ ünyada yaklaşık 34 türe sahip olan Crambe, temel olarak hemikriptofitler, kamefitler ve az sayıda tek yıllık otları içerir. Crambe L. cinsi Türkiye Florasında Brassicaceae familyasının 9. cinsi olarak yer alır. Türkiye Florasının 1. Cildinde (Davis, 1965) 2 tür ve alt taksonları ile birlikte toplam 4 takson yer alırken, daha sonra 10. ciltte (Davis ve ark., 1988) Crambe maritima L yeni kayıt olarak eklenmiştir. Crambe hispanica L. Yıldıztugay ve ark. (2009) tarafından yeni kayıt olarak tespit edilmiştir. Prina (2009) tarafından Crambe orientalis L. var. sulphurea Stapf ex O.E.Schulz'nın Urfa'dan, Crambe grandiflora
DC 'nin Birecik'ten, Crambe orientalis L. var dasycarpa O.E. Schulz 'nın Mersin'den kaydı verilmiştir. Prina (2009), Crambe L. seksiyonunun taksonomik revizyonunda bazı taksonomik değişiklikler önermiş, bu öneriler doğrultusunda Crambe orientalis L. var. sulphurea Stapf ex O. E. Schulz, Crambe orientalis subsp. sulphurea (Stapf ex O.E. Schulz) Prina olarak değiştirilmiştir. Ayrıca Crambe orientalis L var. alutacea (Hand.Mazz.) Hedge \& Hub.-Mor., Prina (2009) tarafından Crambe alutacea Hand.-Mazz. olarak değerlendirilmiştir. Tüm bu yeni kayıtlar ve taksonomik değişikliklerle birlikte Crambe 
L.'nin Türkiye'deki toplam tür sayısı 6, takson sayısı ise 10 'a yükselmiştir.

Etiyopya hardalı olarakta bilinen Crambe (Crambe hispanica subsp. abyssinica) bitkisi, kayalık, taşlık alanlarda yetişen tek yıllık otsu bitkidir. Bitkinin toplam su tüketimi $200-270 \mathrm{~mm}$ arasında değişiklik göstermektedir (Merrill ve ark., 2001). Bitkinin orijininin Doğu Afrika'nın yüksek yerleri ve Akdeniz kuşağı olduğu bildirilmektedir (Weiss, 1983). Ülkemizde ise yalnızca Mersin ilinin Anamur ilçesinde kaydedildiği bildirilmektedir (Evren, 2009). Bitki boyu çevre şartlarına bağlı olarak 1-2 metreye kadar boylanabilmektedir. Çiçek renkleri beyaz veya sarıdır. Tohumları, küçük kapsül içerisinde bulunurlar. Her bir kapsül içerisinde bir adet yeşilimsi kahve renkli 0,8-2,6 mm çaplı yuvarlak tohum bulunur. İç kabuk oranları \%25-30 civarındadır. Küspesindeki protein oranı \%28 civarındadır (Goos ve ark., 2009). Bin tohum ağırlığı ise genellikle 6-10 g arasında değişir (Falasca ve ark., 2010). Crambe tohumunun sabit yağında bulunan yağ asitleri dağılımının \%56,4 erüsik asit, $\% 17,6$ oleik asit ve \%10,9 linoleik asit olduğu bildirilmektedir (Strasil, 2010).

Endüstriyel hareketliliğin intiyaç duyduğu enerjinin ana kaynağı olan petrolün artık tükenme sinyalleri vermesi insanoğlunu yeni enerji kaynakları bulma konusunda farklı arayışlara yöneltmiştir. Bu amaçla bitkisel yağların gıda olarak kullanımının yanı sıra özellikle son yıllarda endüstriyel amaçlı kullanımı da hızla yaygınlaşmaktadır. Bitkisel yağların endüstride kullanım alanları biyodizel, motor ve makine yağlayıcıları, kayganlaştırıcı, biyoplastik, naylon, kozmetik ve boya sanayisi gibi endüstriyel ürünlerin üretimidir. Crambe L. tohumundan elde edilen sabit yağ, yapıştırıcı, kayganlaştırıcı, sentetik kauçuk, motor yağı, tekstil (Falasca ve ark., 2010), parfüm, deterjan, pestisit endüstrilerinde, yazıcı mürekkebi yapımında ve plastik sanayinde kullanılmaktadır (Ericson ve Bassin, 1990).

Mineral yağlardan türevlenerek elde edilen plastikler suda çözünmediğinden doğada parçalanmaya uğramazlar. Fakat nişasta, selüloz ve proteinler gibi doğal polimerlerin yeniden düzenlenmesi ile elde edilen polimerler suda çözülebilir doğada parçalanmaya uğrayarak çevre kirliliğine yol açmazlar (Knights, 2002). Erüsik asitin türevi olarak elde edilen Erukamid'in endüstriyel olarak en önemli uygulama alanı plastik imalatında ve kayganlaştırıcı olarak kullanılmasıdır. Erukamid ayrıca polietilen filmlerde anti-bloke madde olarak, renkli kalem ve parlatıcı yapımında, film ve slâytlarda, yapıştırıcı madde, köpük önleyici, aşınmayı önleyici, viskoziteyi artırıcı olarak kullanılmaktadır (Ericson ve Bassin, 1990).

Ülkemizde ayçiçeği, soya ve kolza gibi yağlı tohumlu bitkiler genellikle sulama imkânı olan veya yeterli yağış alan bölgelerde yetiştirilmektedir. Ancak daha az yağış alan İç Anadolu bölgesinde yağlı tohumlu bitkilerin ekim alanı yok denecek kadar azdır. Anadolu florasında doğal olarak yetişen Crambe türleri kurak bölgelerde yoğun olarak görülmektedir. Crambe hispanica subsp. abyssinica 'nın su tüketiminin diğer yağ bitkileri ile karşılaştırıldığında düşük olduğu görülmüştür (Merrill ve ark., 2001). Bu özelliğiyle Crambe Orta Anadolu bölgesinde alternatif bir yağ bitkisi olma özelliğine sahiptir.

$\mathrm{Bu}$ çalışmanın ana amacı; doğal floramızda çok sayıda yabani türü bulunan Crambe 'nin, Crambe hispanica subsp. abyssinica türünün bazı bitkisel özelliklerini belirlemek ve araştırmacıların dikkatlerini bitkiye çekmektir.

\section{Materyal ve Yöntem}

Bu çalışmada materyal olarak ABD Ulusal Gen Bankası'ndan temin edilen 14 farklı ülkeden toplanmış 82 adet Crambe (Crambe hispanica subsp. abyssinica) genotipi kullanılmıştır.

\section{İklim ve Toprak Özellikleri}

Araştırmanın yapıldığı deneme alanı düz, iyi drenajlı derin ve orta derin, az taşlı, killi-tınlı topraklardan oluşmaktadır. Toprak pH 'sı 8.06, tuz içeriği $\% 0,041$, organik madde $\% 1,57$, kireç oranı \%2,65'dir. Denemenin yürütüldüğü alana yıl boyunca toplam $295 \mathrm{~mm}$ yağış düşmüştür.

\section{Tarla Çalışmaları}

Crambe (Crambe hispanica subsp. abyssinica) genotiplerinin bazı bitkisel özelliklerinin belirlenmesi amacıyla 27.03.2013 tarihinde 82 adet genotip Tarla Bitkileri Merkez Araştırma Enstitüsü Müdürlüğü 'nün kampüsü içerisinde genotip sıralarına ekilmiş ve aşağıda belirtilen gözlem, ölçüm ve deneyler yapılmıştır. Denemede bitki sıklığı $30 \times 5 \mathrm{~cm}$ olacak şekilde ekilmiş ve her genotip sıra uzunluğu 6 metre olarak belirlenmiştir. Sıra 
başlarındaki 0,5 metredeki bitkiler kenar tesiri olarak değerlendirme dışı bırakılmıştır. Deneme süresince yabancı ot temizliği haricinde herhangi bir tarımsal uygulama yapılmamıştır. Bitkilerin hasadı 23.06.2013 tarihinde elle yapılmıştır.

Tarla Denemesinde Alınan Gözlem ve Ölçümler;

1- Sapa kalkma gün sayısı: Genotip sıralarının \%80'nin çıkışından itibaren, bitkilerin \%80'nin sapa kalktığı tarihe kadar geçen gün sayısı sapa kalkma gün sayısı olarak belirlenmiştir.

2- Bin dane ağırlığı: Her genotipe ait tohumlar, 4 kez 100 adet sayılmış, bunların ağırıkları hassas terazide tartılmış ve sonuçların ortalamaları alındıktan sonra 10 ile çarpılıp g olarak ifade edilmiştir.

3- Bitki başına tohum verimi (g/bitki): Kenar tesiri atıldıktan sonra her genotip sırasındaki bitkiler sayılarak hasat edilmiş, tohumların ağırlıkları alınmış ve bitki başına düşen tohum ağırlığı hesaplanmıştır.

4- Tohumda yağ oranı (\%): Her genotip sırasından alınan tohumlar Soxterm 2000 yağ tayin cihazında solvent (petrol eteri) extraksiyonu yöntemi ile yapılmıştır (ISO 659:2009).

5- Sabit yağ asiti bileşenleri (\%): Her genotip sırasından elde edilen yağların yağ asitleri bileşimi belirlemek için; $0,1 \mathrm{~g}$ yağa 10 $\mathrm{ml}$ n-hekzan eklenip çalkalanarak üzerine 0,5 $\mathrm{ml} 2 \mathrm{~N}$ metanollü $\mathrm{KOH}$ ilave edilip karıştırılıp 0,5 saat bekletilerek esterleşme sağlanmış, üst fazdan alınan örnekler Shimadzu AOC-20i otomatik enjektörüne yerleştirilmiş ve Shimadzu GC-2010 (Japonya), alev iyonizasyon dedektörü (FID) ve Teknokroma kapillar kolon (100 m x 0,25 mm ve 0,2 $\mu \mathrm{m}$ film kalınlığı) kullanılarak bakılmıştır. Taşıyıcı gaz olarak helyum $0.94 \mathrm{ml} /$ dakika akış hızı ile uygulanmıştır. Split oranı 1:100 olarak ayarlanmıştır. Çalışma sıcaklıkları enjeksiyon bloğu ve detektör için $250{ }^{\circ} \mathrm{C}$ olarak ayarlanmıştır. Kolon fırınının İzotermal kondisyonu, $140{ }^{\circ} \mathrm{C}$ de 5 dakika bekleyip $4{ }^{\circ} \mathrm{C}$ /dk. Isı artış hızıyla $240{ }^{\circ} \mathrm{C}$ çıkarak $20 \mathrm{dk}$. bekleyecek şekilde programlanmıştır. Yağ asitlerinin tanımlanmasında Restek 35077, Food Industry FAME mix (ABD) standart olarak kullanılmıştır.

\section{Verilerin Değerlendirilmesi}

Araştırma sonucunda elde edilen verilerin istatistiksel hesaplamaları JUMP paket programı kullanılarak yapılmıştır.

\section{Bulgular ve Tartışma}

Crambe genotiplerinden elde edilen rozette kalma gün sayısı, bin tohum ağılığı (g), bitki başına tohum verimi ( $\mathrm{g} / \mathrm{bitki}$ ) ve tohumda yağ oranı (\%) değerleri ile incelenen özelliklere ait istatistik parametrelerden minimum, maksimum, standart sapma ve varyasyon katsayısı değerleri Çizelge 1'de verilmiştir.

Çizelge 1'de görüldüğü gibi Crambe genotiplerindeki rozette kalma gün sayısı 3544 gün, bin tohum ağırlığı 2,6-8,5 g, bitki başına tohum verimi $0,8-5,1 \mathrm{~g} / \mathrm{bitki}$, tohumda yağ oranı \%7,7-21,2 arasında değişim göstermiştir. En yüksek yağ oranı değerini \%21,2 ile PI378589 genotipi; en düşük yağ oranı değerini \%7,7 ile PI 414156 genotipi vermiştir. En yüksek tek bitki verim değerini 5,1 g ile PI305285 genotipi; en düşük tek bitki verim değerini $0.77 \mathrm{~g}$ ile PI 279346 genotipi vermiş̧ir. Bunun yanı sıra PI378589 genotipi $\% 21,1$ yağ oranı ve $3.69 \mathrm{~g}$ tek bitki verimi ile daha iyi bir performans göstermiştir. Yapılan gözlem neticesinde tüm genotiplerin çiçek renginin beyaz olduğu belirlenmiştir. Genotipler, incelenen bazı özellikler bakımından oldukça büyük varyasyon gösterirken bazı özellikler bakımından ise düşük varyasyon göstermiştir. Örneğin sapa kalkma gün sayıları ve bin tohum ağırlıkları bakımından birbirlerine yakın özellikler gösterirken; tek bitki verimi ve yağ oranı bakımından oldukça farklı özellik göstermişlerdir. Genotipler arasındaki farklılıklar materyallerin farklı ülkelerden toplanmış olması ile açıklanabilir.

Çalışmadan elde edilen bulgular bin tohum ağırlığı için Lara-Fioreze ve ark. (2013)'nın bildirdiği $6.38 \mathrm{~g}$, Wang ve ark. (2000)'nın bildirdiği 5,7 g, Fontana ve ark.(1998)'nın bildirdiği $6.84 \mathrm{~g}$, Vollmann ve P. Ruckenbauer (1993)'in bildirdiği 6,9 g değerleri ile benzer özellik gösterirken; yağ oranı için Lara-Fioreze ve ark. (2013)'nın bildirdiği \%28,78; Wang ve ark. (2000)'nın bildirdiği \%34.48, Bondioli ve ark. (1998)'nın bildirdiği \%30,6, Fontana ve ark.(1998)'nın bildirdiği \%32,8-37,9, Vollmann ve P. Ruckenbauer (1993)'in bildirdiği \%31,3 değerlerinden düşük olduğu görülmüştür. 
Arslan et al. "Determination of Some Plants Characteristics of Crambe (Crambe hispanica subsp. abyssinica) Genotypes"

Çizelge 1.Crambe genotiplerinde incelenen özelliklere ait minimum, maksimum, standart sapma ve varyasyon katsayısı değerleri

Table 1. Minimum, maximum, standard deviation and coefficient of variation values of features examined in Crambe genotype

\begin{tabular}{|c|c|c|c|c|}
\hline $\begin{array}{l}\text { Ülkel } \\
\text { Aksesyon no }\end{array}$ & $\begin{array}{c}\text { Sapa kalkma } \\
\text { gün sayısı }\end{array}$ & $\begin{array}{c}1000 \text { Dane ağırlığı } \\
\text { (g) }\end{array}$ & $\begin{array}{c}\text { Tek bitki verimi } \\
(\mathrm{g})\end{array}$ & $\begin{array}{c}\text { Yağ oranı } \\
(\%)\end{array}$ \\
\hline Nebraska/ABD (NSL74248) & 42 & 5,83 & 1,82 & 17,3 \\
\hline Nebraska/ABD (NSL74251) & 43 & 5,92 & 3,32 & 16,1 \\
\hline Nebraska/ABD (NSL74252) & 43 & 6,1 & 3,24 & 13,8 \\
\hline Nebraska/ABD (NSL74253) & 43 & 6,38 & 4,7 & 12,3 \\
\hline Nebraska/ABD (NSL74254) & 43 & 6,19 & 3,57 & 12,3 \\
\hline Nebraska/ABD (NSL74257) & 43 & 5,6 & 3,89 & 12,3 \\
\hline Nebraska/ABD (NSL74258) & 43 & 2,63 & 4,07 & 12,3 \\
\hline Nebraska/ABD (NSL74261) & 39 & 6,64 & 1,86 & 10,7 \\
\hline Nebraska/ABD (NSL74264) & 39 & 6,09 & 1,7 & 12,4 \\
\hline Nebraska/ABD (NSL74265) & 39 & 6,09 & 2,19 & 11,4 \\
\hline Nebraska/ABD (NSL74266) & 39 & 7,27 & 1,82 & 13,9 \\
\hline Nebraska/ABD (NSL74267) & 39 & 6,7 & 2,83 & 14,3 \\
\hline Nebraska/ABD (NSL74269) & 39 & 5,92 & 2,53 & 14,3 \\
\hline Nebraska/ABD (NSL74270) & 39 & 6,87 & 2,17 & 19,4 \\
\hline Nebraska/ABD (NSL74271) & 39 & 7,04 & 2,05 & 11,6 \\
\hline Nebraska/ABD (NSL74272) & 39 & 6,81 & 2,82 & 15 \\
\hline Nebraska/ABD (NSL74278) & 39 & 5,59 & 2,55 & 17 \\
\hline İndiana/ABD (NSL77602) & 39 & 6,65 & 2,69 & 14,5 \\
\hline Connecticut/ABD (PI189139) & 39 & 7,72 & 2,84 & 16,4 \\
\hline ISVEÇ (PI247310) & 39 & 6,09 & 2,84 & 16,1 \\
\hline ETIYOPYA (PI279346) & 35 & 7,28 & 0,77 & 18,2 \\
\hline ESKI S.S.C.B (PI281728) & 39 & 6,65 & 1,88 & 14,6 \\
\hline ESKI S.S.C.B (PI281729) & 39 & 6,36 & 4,14 & 10,7 \\
\hline ESKI S.S.C.B (PI281730) & 39 & 5,48 & 3,25 & 13,7 \\
\hline ESKI S.S.C.B (PI281731) & 39 & 5,96 & 1,2 & 11,3 \\
\hline ESKI S.S.C.B (PI281732) & 39 & 6,62 & 2,1 & 12,6 \\
\hline ESKI S.S.C.B (PI281733) & 39 & 7,32 & 1,28 & 11,4 \\
\hline ESKI S.S.C.B (PI281734) & 42 & 6,53 & 1,18 & 15,9 \\
\hline ESKI S.S.C.B (PI281735) & 42 & 6,51 & 1,14 & 19,3 \\
\hline ESKI S.S.C.B (PI281736) & 40 & 6,41 & 1,33 & 14,1 \\
\hline UKRAYNA (PI281737) & 40 & 6,28 & 2,55 & 15,6 \\
\hline DANIMARKA (PI304399) & 39 & 6,43 & 3,73 & 9,6 \\
\hline İSVEÇ (PI305283) & 42 & 6,69 & 2,44 & 13,4 \\
\hline İSVEÇ (PI305284) & 38 & 6,61 & 3,84 & 11 \\
\hline ISVEÇ (PI305285) & 43 & 6,74 & 5,15 & 14,1 \\
\hline İSVEÇ (PI305286) & 43 & 5,87 & 2,58 & 13,8 \\
\hline İSVEÇ (PI 305288) & 40 & 5,8 & 2,77 & 12,2 \\
\hline ROMANYA (PI306422) & 42 & 6,22 & 3,3 & 8,4 \\
\hline POLONYA (PI311740) & 42 & 5,82 & 4,28 & 12,5 \\
\hline KANADA (PI319691) & 39 & 6,76 & 2,38 & 12,7 \\
\hline
\end{tabular}


Arslan ve ark. "Crambe (Crambe hispanica subsp. abyssinica) Genotiplerinin Bazı Bitkisel Özelliklerinin Belirlenmesi"

Çizelge 1'in devamı

Table 1 continued

\begin{tabular}{|c|c|c|c|c|}
\hline $\begin{array}{l}\text { Ülke/ } \\
\text { Aksesyon no }\end{array}$ & $\begin{array}{c}\text { Sapa kalkma } \\
\text { gün sayısı }\end{array}$ & $\begin{array}{c}1000 \text { Dane ağırlığı } \\
(\mathrm{g})\end{array}$ & $\begin{array}{c}\text { Tek bitki } \\
\text { verimi (g/bitki) }\end{array}$ & $\begin{array}{c}\text { Yağ oranı } \\
(\%)\end{array}$ \\
\hline ETIYOPYA (PI326569) & 39 & 7,69 & 1,32 & 11,2 \\
\hline ROMANYA (PI337110) & 39 & 6,04 & 0,92 & 13,5 \\
\hline ISVEÇ (PI360888) & 39 & 6,14 & 1,53 & 13,9 \\
\hline İSVEÇ (PI360890) & 43 & 5,61 & 1,55 & 12,7 \\
\hline İSVEÇ (PI360891) & 39 & 5,74 & 2,07 & 10,6 \\
\hline ISVEÇ (PI360892) & 39 & 6,54 & 1,39 & 13,8 \\
\hline ISVEÇ (PI360893) & 39 & 6,7 & 1,42 & 13,8 \\
\hline TÜRKIYE (PI370747) & 39 & 7,27 & 1,7 & 13,0 \\
\hline ISPANYA (PI372925) & 43 & 6,87 & 3,72 & 12,0 \\
\hline Maryland/ABD (PI 378589) & 43 & 5,84 & 3,69 & 21,2 \\
\hline ETIYOPYA (PI384520) & 43 & 7,93 & 2,83 & 10,8 \\
\hline ETIYOPYA (PI384521) & 43 & 6,28 & 1,96 & 10,4 \\
\hline ETIYOPYA (PI384522) & 43 & 7,56 & 1,49 & 21,1 \\
\hline ETIYOPYA (PI384523) & 43 & 6,3 & 1,05 & 11,1 \\
\hline ETIYOPYA (PI384524) & 43 & 7,77 & 1,45 & 13,4 \\
\hline ETIYOPYA (PI384525) & 43 & 8,06 & 1,69 & 14,5 \\
\hline ETIYOPYA (PI384526) & 43 & 7,61 & 1,55 & 18,4 \\
\hline ETIYOPYA (PI384528) & 38 & 6,5 & 2,36 & 9,7 \\
\hline ETIYOPYA (PI384529) & 43 & 7,35 & 1,69 & 10,4 \\
\hline ETIYOPYA (PI384530) & 43 & 7,03 & 2,18 & 12,1 \\
\hline ETIYOPYA (PI384531) & 43 & 7,08 & 2,13 & 10,9 \\
\hline ETIYOPYA (PI384532) & 44 & 6,99 & 1,91 & 10,4 \\
\hline ETIYOPYA (PI384533) & 44 & 6,83 & 1,62 & 12,8 \\
\hline ISPANYA (PI392071) & 44 & 7,59 & 1,37 & 13,4 \\
\hline ISPANYA (PI392072) & 44 & 7,02 & 1,25 & 9,2 \\
\hline TÜRKIYE (PI392326) & 44 & 7,23 & 0,86 & 17,3 \\
\hline TÜRKIYE (PI392327) & 44 & 6,57 & 2,06 & 11,2 \\
\hline ESKI S.S.C.B (PI393513) & 42 & 6,78 & 2,91 & 11,3 \\
\hline ESKI S.S.C.B (PI393514) & 39 & 6,5 & 2,0 & 12,4 \\
\hline ESKI S.S.C.B (PI393515) & 39 & 6,11 & 3,63 & 14,4 \\
\hline lowa/ABD (PI414156) & 39 & 6,21 & 3,05 & 7,7 \\
\hline İndiana/ABD (PI514649) & 42 & 6,94 & 1,61 & 11,8 \\
\hline İndiana/ABD (PI514650) & 43 & 6,51 & 1,32 & 11,6 \\
\hline Maryland/ABD (PI 533664) & 42 & 6,64 & 2,1 & 9,3 \\
\hline Maryland/ABD (PI 533665) & 41 & 6,06 & 1,31 & 15,5 \\
\hline Maryland/ABD (PI 533666) & 41 & 6,27 & 1,68 & 12,7 \\
\hline Maryland/ABD (PI 533667) & 41 & 6,96 & 2,09 & 14,8 \\
\hline Maryland/ABD (PI 533668) & 41 & 7,44 & 2,51 & 14,9 \\
\hline ETIYOPYA (PI633195) & 42 & 8,48 & 1,96 & 19,7 \\
\hline New Mexico/ABD (PI633196) & 42 & 6,89 & 2,73 & 15,3 \\
\hline ALMANYA (PI633197) & 43 & 6,6 & 2,3 & 11,4 \\
\hline KENYA (PI633198) & 43 & 6,19 & 2,14 & 13,9 \\
\hline Minimum & 35 & 2,6 & 0,8 & 7,7 \\
\hline Maksimum & 44 & 8,5 & 5,1 & 21,2 \\
\hline Ortalama & 41 & 6,6 & 2,3 & 13,4 \\
\hline Standart Sapma & 2,1 & 0,8 & 1 & 2,8 \\
\hline Var. Katsayısı & 5 & 11,7 & 41,3 & 20,8 \\
\hline
\end{tabular}


Crambe genotiplerinden elde edilen sabit yağ asidi bileşeni değerlerine ait istatistik parametrelerden minimum, maksimum, standart sapma ve varyasyon katsayısı değerleri Çizelge 2'de verilmiştir. Çizelge 2'de görüldüğü gibi Crambe genotiplerinde dört yağ asidi ön plana çıkmıştır. Bunlar \%45,05-56,25 ile erüsik asit, \%9,22-15,47 ile oleik asit, \%0,812,23 ile linoleik asit ve \%6,05-9,97 ile de linolenik asit olmuştur. Ana bileşenler bakımından genotipler arasında çok büyük farklılıklar gözlenmezken; Cis-11,14Eikosadinoik asit içeriği bakımından oldukça yüksek bir farklılık gözlenmiştir (Çizelge 2).
Çalışmadan elde edilen yağ asiti bulguları, Strasil (2010)'in bildirdiği \%56,4 erüsik asit, $\% 17,6$ oleik asit ve $\% 10,9$ linoleik asit değerleri; Bondioli ve ark. (1998)'nın bildirdiği \%56,2 erüsik asit, $\% 17,2$ oleik asit, $\% 8,7$ linoleik asit ve $\% 5,2$ linolenik asit değerleri; Wang ve ark. (2000)'nın bildirdiği \% 55,9-63,51 erüsik asit, $\% 16,49$ oleik asit, $\% 9,34$ linoleik asit ve $\% 4,8$ linolenik asit değerleri; Vollmann ve $P$. Ruckenbauer (1993)'in bildirdiği \%58,9 erüsik asit, $\% 17$ oleik asit, \%9,3 linoleik asit ve \%8,5 linolenik değerleri ile benzer özellikler göstermiştir.

Çizelge 2.Crambe genotiplerinin sabit yağ asiti bileşenlerine ait minimum, maksimum, standart sapma ve varyasyon katsayısı değerleri (\%)

Table 2. Minimum, maximum, standard deviation and coefficient of variation values of fatty acid components in Crambe genotype (\%)

\begin{tabular}{|c|c|c|c|c|c|c|c|c|c|c|c|c|c|c|c|}
\hline $\begin{array}{l}\text { Ülke } \\
\text { IAksesyon no }\end{array}$ & 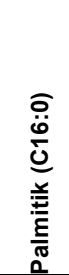 & 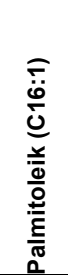 & 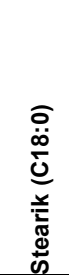 & 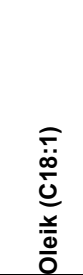 & 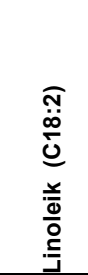 & 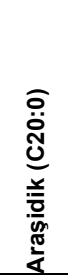 & 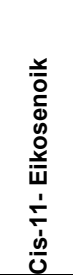 & 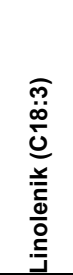 & 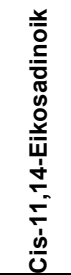 & 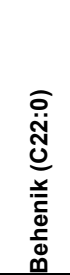 & 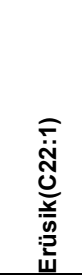 & 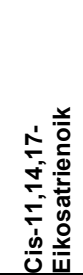 & 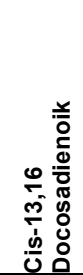 & 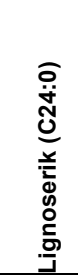 & 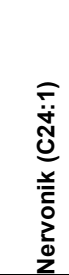 \\
\hline ABD (NSL74248) & 2,83 & 0,26 & 1,34 & 14,15 & 12,23 & 1,01 & 5,05 & 9,43 & 1,74 & 1,85 & 45,05 & 1,74 & 0,80 & 0,74 & 1,51 \\
\hline ABD (NSL74251) & 2,61 & 0,26 & 1,23 & 14,74 & 10,71 & 1,02 & 4,13 & 9,97 & 0,40 & 2,05 & 47,63 & 1,68 & 0,80 & 0,80 & 1,56 \\
\hline ABD (NSL74252) & 2,00 & 0,26 & 0,85 & 13,61 & 9,64 & 0,86 & 2,26 & 7,64 & 0,24 & 2,25 & 54,90 & 1,72 & 0,91 & 0,86 & 1,74 \\
\hline ABD (NSL74253) & 2,03 & 0,29 & 0,86 & 13,66 & 9,79 & 0,89 & 2,28 & 7,93 & 0,25 & 2,26 & 54,10 & 1,90 & 0,93 & 0,86 & 1,70 \\
\hline ABD (NSL74254) & 2,06 & 0,23 & 0,90 & 13,83 & 9,52 & 0,85 & 2,31 & 7,65 & 0,24 & 2,22 & 54,90 & 1,54 & 0,88 & 0,86 & 1,74 \\
\hline ABD (NSL74257) & 2,04 & 0,23 & 0,88 & 14,38 & 9,50 & 0,83 & 2,37 & 7,59 & 0,24 & 2,22 & 54,53 & 1,52 & 0,85 & 0,84 & 1,73 \\
\hline ABD (NSL74258) & 2,02 & 0,25 & 0,84 & 13,84 & 9,42 & 0,81 & 2,35 & 7,75 & 0,24 & 2,18 & 54,91 & 1,66 & 0,88 & 0,85 & 1,75 \\
\hline ABD (NSL74261) & 2,07 & 0,26 & 0,86 & 14,11 & 9,41 & 0,79 & 2,49 & 7,68 & 0,24 & 2,15 & 54,42 & 1,67 & 0,86 & 0,81 & 1,77 \\
\hline ABD (NSL74264) & 2,25 & 0,29 & 0,94 & 15,21 & 9,61 & 0,84 & 2,96 & 7,78 & 0,27 & 2,12 & 52,47 & 1,65 & 0,81 & 0,81 & 1,75 \\
\hline ABD (NSL74265) & 2,51 & 0,24 & 0,98 & 14,84 & 11,78 & 0,78 & 2,39 & 7,23 & 0,25 & 2,05 & 51,82 & 1,56 & 0,79 & 0,79 & 1,64 \\
\hline ABD (NSL74266) & 1,96 & 0,25 & 0,80 & 14,16 & 9,33 & 0,80 & 2,57 & 7,41 & 0,26 & 2,16 & 54,94 & 1,63 & 0,88 & 0,83 & 1,77 \\
\hline ABD (NSL74267) & 2,22 & 0,20 & 0,93 & 15,03 & 9,01 & 0,83 & 3,06 & 7,62 & 0,26 & 2,07 & 53,68 & 1,43 & 0,77 & 0,78 & 1,73 \\
\hline ABD (NSL74269) & 1,97 & 0,24 & 0,84 & 14,38 & 9,56 & 0,82 & 2,86 & 7,41 & 0,25 & 2,04 & 54,54 & 1,52 & 0,83 & 0,79 & 1,72 \\
\hline ABD (NSL74270) & 2,61 & 0,24 & 1,18 & 15,03 & 10,48 & 0,88 & 4,25 & 9,86 & 0,46 & 1,91 & 47,51 & 1,55 & 0,73 & 0,76 & 1,66 \\
\hline ABD (NSL74271) & 1,87 & 0,22 & 0,74 & 14,33 & 9,14 & 0,71 & 2,34 & 7,42 & 0,23 & 2,10 & 55,38 & 1,62 & 0,85 & 0,82 & 1,84 \\
\hline ABD (NSL74272) & 1,93 & 0,23 & 0,80 & 14,72 & 9,00 & 0,77 & 2,64 & 7,06 & 0,23 & 2,15 & 55,19 & 1,58 & 0,82 & 0,83 & 0,81 \\
\hline ABD (NSL74278) & 2,00 & 0,24 & 0,84 & 14,36 & 9,20 & 0,75 & 2,56 & 7,35 & 0,23 & 2,13 & 55,08 & 1,56 & 0,82 & 0,83 & 1,81 \\
\hline ABD (NSL77602) & 1,90 & 0,23 & 0,77 & 14,33 & 9,01 & 0,77 & 2,29 & 7,68 & 0,23 & 2,13 & 55,38 & 1,58 & 0,82 & 0,81 & 1,77 \\
\hline ABD (PI189139) & 1,93 & 0,22 & 0,77 & 14,25 & 8,99 & 0,73 & 2,30 & 7,47 & 0,23 & 2,13 & 55,70 & 1,54 & 0,82 & 0,82 & 1,81 \\
\hline ISVEÇ (PI247310) & 1,96 & 0,24 & 0,74 & 14,31 & 9,16 & 0,73 & 2,43 & 7,42 & 0,22 & 2,11 & 55,32 & ,59 & 0,82 & 0,84 & 1,83 \\
\hline ETIYOPYA (PI279346) & 2,18 & 0,19 & 0,98 & 14,73 & 9,78 & 1,05 & 2,57 & 6,37 & 0,25 & 2,29 & 24 & 1,25 & 0,82 & 0,77 & 1,40 \\
\hline ESKI S.S.C.B (PI281728) & 1,95 & 0 & 0,77 & 1 & 9 & 3 & 36 & 0 & 5 & 2,10 & 47 & 1,37 & 0,82 & 0,82 & 1,82 \\
\hline ESKI S.S.C.B (PI281729) & 1,95 & 0,25 & 0,77 & 13,78 & 9,61 & 0,74 & 2,33 & 7,81 & 0,25 & 2,08 & 54,49 & 1,76 & 0,82 & 0,85 & 0,76 \\
\hline ESKI S.S.C.B (PI281730) & 2,05 & 0,26 & 0,83 & 13,98 & 9,73 & 0,82 & 2,64 & 7,33 & 0,27 & 2,23 & 54,32 & 1,65 & 0,82 & 0,85 & 0,77 \\
\hline ESKI S.S.C.B (PI281731) & 2,11 & 0,25 & 0,85 & 14,56 & 9,53 & 0,80 & 2,78 & 7,37 & 0,25 & 2,15 & 54,06 & 1,58 & 0,82 & 0,83 & 1,78 \\
\hline ESKI S.S.C.B (PI281732) & 2,08 & 0,28 & 0,83 & 14,55 & 9,78 & 0,81 & 2,79 & 7,52 & 0,26 & 2,13 & 53,50 & 1,65 & 0,82 & 0,82 & 1,76 \\
\hline ESKI S.S.C.B (PI281733) & 2,11 & 0,26 & 0,89 & 14,62 & 9,87 & 0,83 & 2,91 & 7,25 & 0,27 & 2,18 & 53,57 & 1,59 & 0,82 & 0,81 & 1,76 \\
\hline ESKI S.S.C.B (PI281734) & 2,11 & 0,23 & 0,90 & 14,34 & 9,57 & 0,79 & 2,62 & 7,43 & 0,29 & 2,10 & 54,35 & 1,56 & 0,82 & 0,82 & 1,78 \\
\hline ESKI S.S.C.B (PI281735) & 2,01 & 0,24 & 0,84 & 14,58 & 9,55 & 0,81 & 2,83 & 7,22 & 0,25 & 2,11 & 54,45 & 1,48 & 0,82 & 0,81 & 1,76 \\
\hline ESKI S.S.C.B (PI281736) & 1,98 & 0,23 & 0,78 & 14,24 & 9,34 & 0,74 & 2,32 & 7,43 & 0,23 & 2,13 & 55,13 & 1,62 & 0,82 & 0,82 & 1,81 \\
\hline UKRAYNA (PI281737) & 2,07 & 0,24 & 0,84 & 13,92 & 9,52 & 0,76 & 2,39 & 7,51 & 0,23 & 2,17 & 54,89 & 1,64 & 0,82 & 0,84 & 1,85 \\
\hline DANIMARKA (PI304399) & 2,05 & 0,27 & 0,83 & 14,50 & 9,58 & 0,80 & 2,66 & 7,60 & 0,26 & 2,07 & 53,97 & 1,70 & 0,82 & 0,85 & 1,74 \\
\hline ISVEÇ (PI305283) & 2,20 & 0,28 & 0,93 & 14,53 & 9,46 & 0,80 & 2,71 & 7,18 & 0,22 & 2,18 & 54,04 & 1,72 & 0,82 & 0,86 & 1,85 \\
\hline ISVEÇ (PI305284) & 1,99 & 0,27 & 0,78 & 14,06 & 9,37 & 0,75 & 2,36 & 7,74 & 0,25 & 2,13 & 54,50 & 1,77 & 0,82 & 0,82 & 1,80 \\
\hline İSVEÇ (PI305285) & 1,98 & 0,23 & 0,81 & 15,37 & 8,80 & 0,80 & 2,96 & 6,81 & 0,22 & 2,09 & 54,96 & 1,44 & 0,82 & 0,78 & 1,70 \\
\hline
\end{tabular}


Çizelge 2'nin devamı

Table 2 continued

\begin{tabular}{|c|c|c|c|c|c|c|c|c|c|c|c|c|c|c|c|}
\hline $\mathrm{ke} / \mathrm{l}$ & 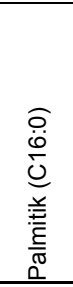 & 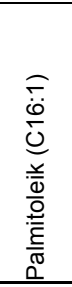 & 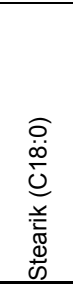 & 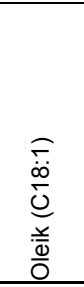 & 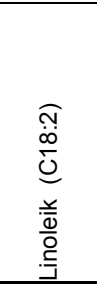 & 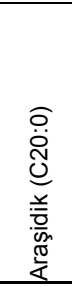 & 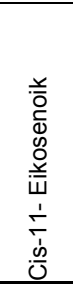 & 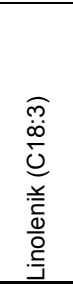 & 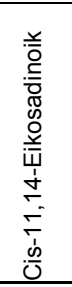 & 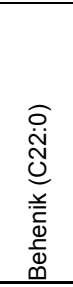 & 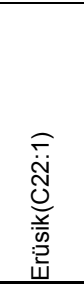 & 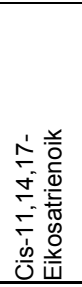 & 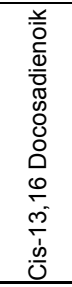 & 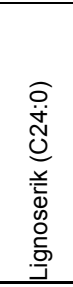 & 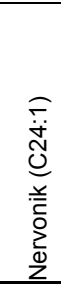 \\
\hline ISVEÇ (PI305286) & 1,99 & 0,24 & 0,78 & 13,77 & 9,55 & 0,75 & 2,47 & 8,37 & 0,25 & 2,10 & 54,57 & 1,73 & 0,82 & 0,85 & 1,75 \\
\hline ISVEÇ & 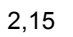 & 0,28 & 0,89 & 14,04 & ,99 & 34 & 2,89 & 7,69 & 0,27 & 20 & 2,66 & 1,73 & 82 & 39 & 78 \\
\hline ROM & 1 & 0,28 & 0,78 & 51 & 70 & 0 & 31 & 39 & 0,26 & 21 & 24 & 1,92 & 82 & 91 &, 79 \\
\hline POLC & 2,25 & 0,31 & 0,91 & 14,31 & 0,24 & 88 & 3,13 & 68 & 0,31 & 2,17 & 2,36 & 1,64 & 0,82 &, 85 &, 75 \\
\hline KANADA (PI319691) & 2,02 & 0,26 & 0,81 & 14,19 &, 73 & 0,77 & 2,55 & 7,50 & 0,25 & 2,17 & 54,21 & 1,62 & 0,82 & 0,83 & 1,82 \\
\hline ETIYOP & 1,90 & 0,25 & 0,74 & 13,66 & 9,25 & 0,74 & 2,24 & 7,69 & 0,24 & 2,17 & 4,85 & 1,82 & 0,82 & 0,90 & 1,81 \\
\hline RON & 1,97 & 0,24 & 0,80 & 14,58 & 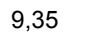 & 79 & 2,50 & 7,38 & 0,25 & 17 & 54 & 1,59 & 0,82 & 85 & 1,81 \\
\hline ISVE & & 0,27 & 0,84 & 14,46 & $y, \angle 3$ & 1 & 2,36 & & 0,22 & $2, \angle U$ & 77 & 1,67 & 0,82 & 35 & 1,82 \\
\hline & 2,25 & 0,30 & 0,94 & 13,52 & 10,41 & 0,82 & 2,90 & 7,67 & 0,31 & 2,15 & 2,96 & 1,76 & 0,82 &, 89 & 83 \\
\hline & 3 & 0,35 & 0,81 & 14,40 & ,70 & 0,77 & 2,58 & 7,70 &, 25 & 2,11 & 3,65 & 1,82 & 0,82 & 0,83 &, 77 \\
\hline ISVE & 2,10 & 0,26 & 0,87 & 14,65 & 9,37 & 0,83 & 2,76 & 7,28 & 0,26 & 2,19 & 4,23 & 1,56 & 0,82 & 0,83 &, 75 \\
\hline ISVE & 2,03 & 0,24 & 0,82 & 14,47 & 9,39 & 0,78 & 2,43 & 7,40 & 0,24 & 2,18 & 4,54 & 1,64 & 0,82 & 0,81 & ,80 \\
\hline TÜR & & 0,24 & 0,78 & 14, & 9 & 78 & 2 & 34 & 0,23 & & & 1,47 & 0,82 & & 85 \\
\hline ISPA & & 0,23 & 0,83 & 14,17 & & & & 1,42 & 0,21 & & 81 & 1,56 & 0,82 & & 1,83 \\
\hline $\mathrm{ABL}$ & 2 , & 0,23 & 1,14 & 15,31 & 10,10 & ,90 & 4,41 & 9,92 & 0,44 & 1,81 & 7,78 & 1,42 & 0,82 & 13 &, 56 \\
\hline ETI & 1,96 & 0,27 & 0,80 & 14,09 & 13 & 0,75 & 2,30 & 8,15 & 0,24 & 2,12 & 54,71 & 1,73 & 0,82 & 0,82 & ,78 \\
\hline ETI & 2,06 & 0,31 & 0,88 & 13,74 & 0,14 & 0,81 & 2,66 & 8,05 & 0,30 & 2,19 & 09 & 1,84 & 0,82 & 0,89 & 84 \\
\hline & & & & & & & & & & & & $\begin{array}{c}1,74 \\
1,71\end{array}$ & $\begin{array}{l}82 \\
82\end{array}$ & & 81 \\
\hline Ti & 3 & 24 & 0,79 & 13,91 & 9,29 & 0,75 & 2,23 & 7,93 & 0,24 & 2,18 & 4,98 & 1,69 & 0,82 & 0,84 & 83 \\
\hline ETIYC & م० & 0,24 & 0,76 & 13,67 & 915 & 74 & 2,16 & 8,08 & 0,23 & 214 & 96 & 1,72 & 0,82 & 39 & 83 \\
\hline & & 23 & & & & & & & 24 & & & 1,50 & 0,82 & & 36 \\
\hline & & 28 & & & 0,68 & & & & 25 & & & 1,73 & 0,82 & & 74 \\
\hline & & 24 & 0,8 & 9 & 33 & 78 & 2,32 & 46 & 0,23 & 2,2 & 11 & 1,57 & 0,82 & 30 & 78 \\
\hline ETIY & 2 & 0,25 & 0,79 & 14,28 & 9,22 & 0,78 & 2,39 & 7,81 & 0,24 & 2,13 & 93 & 1,62 & 0,82 & 0,81 & 73 \\
\hline ETIYY & & 0,25 & 066 & 9,22 & חק & 34 & 2,41 & 7,62 & 18 & & & 1,65 & 0,82 & 3 & 27 \\
\hline & & & & & & & & & 3 & & & 1,66 & 0,82 & & 81 \\
\hline & & 23 & & & & & & & 23 & & & 1,63 & 0,82 & & 71 \\
\hline & 1 & 20 & 0 & 15,47 & 8,27 & 0,80 & 2,78 & 7,48 & 0,23 & 2,14 & 66 & 1,38 & 0,82 & 0 & 73 \\
\hline & 09 & 25 & 0,88 & 15,05 & 9,23 & 33 & 2,89 & 44 & 25 & 21 & 59 & 1,63 & 0,82 & 0,82 & 76 \\
\hline & & 0,21 & & 14 & & 0,77 & & 7,17 & 22 & & & 1,60 & 0,82 & & 77 \\
\hline & & 0,30 & & & & & & & 0,25 & & & 1,57 & 0,82 & & 79 \\
\hline ESK & & 0,2 & & & & & & & 5 & & & 1,58 & 0,82 & & 34 \\
\hline & & & & & & & & & & & & 1,53 & 0,82 & & 66 \\
\hline & 2 & 25 & 0,84 & 4,26 & $9,6 \mathrm{C}$ & 0,8 & 2,70 & 7,6 & 0,26 & 2 & 15 & 1,55 & 0,82 & 32 & 79 \\
\hline lowe & 2,26 & 0,30 & 0,93 & 15,00 & $a_{3}$ & 0,85 & 3,35 & 6,71 & 0,26 & 2,17 & 56 & 1,62 & 0,82 &, 86 &, 79 \\
\hline & 1,85 & 0,19 & 0,8 & 15,40 & & 90 & 2,66 & 6,05 & 23 & ? & & 1,19 & 0,82 & 77 & 51 \\
\hline & & & & & & & & & 8 & & & 1,59 & 0,82 & 2 & 77 \\
\hline & & & & & & & & & 0,25 & & & 2 & 32 & & 51 \\
\hline & & 0,22 & & & & $0, \varepsilon$ & & & 0,23 & & 3 & 1,51 & 0,82 & 0,81 & 64 \\
\hline & 2,18 & 24 & 0,95 & 14,85 & 8,8 & 0,9 & 2,50 & 6,83 & 0,23 & 2,19 & & 1,47 & 0,82 & 78 & ,53 \\
\hline BD (PI 533667) & 1,95 & 0,21 & 0,81 & 14,30 & 9,36 & 0,88 & 2,00 & 6,77 & 0,21 & 2,23 & 6,25 & 1,50 & 0,82 & 0,78 & 1,60 \\
\hline 668) & 2,06 & 0,22 & 0,81 & 14,57 & 9, & 0,83 & 2,53 & 6,84 & 0,24 & 2,09 & 43 & 1,41 & 0,82 & 78 & 62 \\
\hline & & & & & & & & & & & & 4 & 0,82 & & 54 \\
\hline & & 20 & & & & & & & & & & 1,33 & 0,82 & & 45 \\
\hline & 2,16 & 0,28 & 0,83 & 14,18 & 9,87 & 0,78 & 2,63 & 7,68 & 0,26 & 2,14 & 3,84 & 1,62 & 0,82 & 0,80 & ,77 \\
\hline KENYA (PI633198) & 2,13 & 0,24 & 0,86 & 14,14 & 9,34 & 0,82 & 2,54 & 7,77 & 0,26 & 2,11 & 54,52 & 1,59 & 0,82 & 0,82 & 1,75 \\
\hline Min & 0,04 & 0,19 & 0,66 & 9,22 & 0,80 & 0,71 & 2,00 & 6,05 & 0,21 & 1,81 & 5,05 & 1,19 & 0,73 & 0,73 &, 27 \\
\hline & & & & & & & & & & & & 1,92 & 0,93 & 91 & ,86 \\
\hline & & $<J$ & $0, \mathrm{c}$ & T, & &,$c$ & 2,01 & 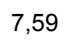 & 0,30 & 2,13 & 4,00 & 1,60 & 0,82 & 0,83 & ,68 \\
\hline & 03 & 0,00 & 0,01 & 0,08 & 0,12 & 0,02 & 0,06 & 0,08 & 0,03 & 0,01 & 0,22 & 0,01 & 0,00 & 0,00 & 03 \\
\hline Stan. & 0,30 & 0,03 & 0,12 & 0,75 & 1,13 & 0,18 & 0,53 & 0,69 & 0,27 & 0,08 & 1,99 & 0,13 & 0,02 & 0,04 & 0,28 \\
\hline
\end{tabular}




\section{Sonuç}

Çalışmadan elde edilen verilere göre genotiplerin yağ oranının oldukça düşük olduğunu görülmektedir. Ancak yağ asiti dağılımındaki yüksek erüsik asit oranı sanayide değerlendirilebilecek bir bitki olduğunu göstermektedir. Ayrıca bitkinin çok düşük yağış oranlarında yetişebiliyor olması ülkemizin benzer bölgelerinde yetişebileceğini göstermektedir.

\section{Kaynaklar}

Bondioli, P., Folegatti, L., Lazzeri, L. ve Palmieri, S., 1998. Native Crambe abyssinica Oil and Its Derivatives as Renewable Lubricants: an Approach to Improve its Quality by Chemical and Biotechnological Processes. Industrial Crops and Products, 7(2): 231-238.

Davis, P.H., 1965. Flora of Turkey and East Eagen Islands. Edinburgh at the University Press, 1: 272-273

Davis, P.H., Mill, R.R., Tan K., 1988, Flora of Turkey and the East Aegean Islands vol.10 (Suppl.), Edinburgh University Press, Edinburgh, pp.186-189.

Falasca, S.L., Flores, N., Lamas, M.C., Carballo, S.M., Anschau, A., 2010. Crambe abyssinica: An Almost Unknown Crop with a Promissory Future to Produce Biodiesel in Argentina, International Journal of Hydrogen Energy, 35 (2010), pp. $5808-5812$

Fontana, F., Lazzeri, L., Malaguti, L., and Galletti, S. 1998. Agronomic characterization of some, Crambe abyssinica genotypes in a Locality of the Po Valley. European Journal of Agronomy, 9(2): 117-126.

Goos, R. J., Johnson, B., and Bourguignon, C., 2009. Preliminary Evaluation of the Soil Application Value of Crambe meal. Communications in Soil Science and Plant Analysis, 40(21-22), 3211-3224.

Knights, S.E., 2002. Crambe: A North Dakota Case Study, A Report for the Rural Industries Research and Development Corporation, RIRDC Publication No W02/005,RIRDC, Project No TA001-55.Zellulose in Hölzern und Zellstoffen, Technologie und Chemie der Papieru. Zellstoff-Fabrikation, 26: 125-139.
Lara-Fioreze, A. C. C., Tomaz, C. A., Fioreze, S. L., Pilon, C., \& Zanotto, M. D., 2013. Genetic diversity among progenies of Crambe abyssinica Hochst for seed traits. Industrial Crops and Products, 50: 771-775.

Merrill S. D., Tanaka D. L., Krupinsky J. M., and Ries R. E., 2001. Safflower Root Growth And Water Use In Comparison With Other Crops, 5th International Safflower Conference, Williston, N.D. , USA, July 23-27, pp. 227-231

Prina, A. 2009. Taxonomic Review of the Genus Crambe Sect. Crambe (Brassicaceae, Brassiceae). Anales Jard. Bot. Madrid 66(1): 7-24.

Strasil, Z., 2010. Impact of Some Selected Agricultural Measures and Site Conditions on Economically Significant Characteristics of Crambe. Scientia Agriculturae Bohemica, Vol. 41 No. 2. 2010 , pp. $77-83$

Vollmann, J. ve Ruckenbauer, P. (1993). Agronomie Performance and Oil Quality of Crambe as Affected By genotype and Environment. (https://diebodenkultur.boku.ac.at/volltexte/ba nd-44/heft-4/vollmann.pdf) (Erişim tarihi: 24.11.2014)

Wang, Y. P., Tang, J. S., Chu, C. Q., and Tian, J. (2000). A Preliminary Study on the Introduction and Cultivation of Crambe abyssinica in China, an Oil Plant for Industrial Uses. Industrial Crops and Products, 12(1), 47-52.

Weiss EA., 1983. Crambe, Niger and Jojoba. Tropical Agriculture Series, Longman Group Ltd, Oilseed Crops, Chapter 10, pp. 463-85.

Yıldıztugay, E., Küçüködük, M., Özel, M., Özdemir, C., 2009. A New Record for the Flora of Turkey: Crambe hispanica L. (Brasssicaceae), Turk J Bot., 33 (2009): 227230 